\title{
1,3,4-Thiadiazoles in the design and synthesis of new star-shaped mesogens displaying columnar liquid crystal properties.
}

\author{
A. I. Sánchez ${ }^{a^{\star}}$, M. L. Parra ${ }^{a}$, J. M. Vergara ${ }^{a}$, J. A. Ulloa ${ }^{a}$ \\ ${ }^{a}$ Facultad de Ciencias Químicas, Departamento de Química Orgánica, Universidad de Concepción, Casilla \\ 160-C, Concepción, Chile \\ ansanchez@udec.cl
}

Keywords: Liquids Crystals, Columnar, Thiadiazole

\section{INTRODUCTION}

Recently, columnar materials have acquired great attention due to their potential technological applications. ${ }^{1}$ The introduction of a thiadiazole ring within the main structure opens the possibility of generating new mesogenic units. It causes changes in the polarity, polarizability and geometry, due to the associated dipole moment. ${ }^{2}$ In this work we report the synthesis and mesomorphic properties of new columnar liquid crystals with benzene and/or triazine cores and three pendant $n$-alkoxyphenyl1,3,4-thiadiazole arms (la-b and Ila-b respectively). The synthetic route is shown in scheme 1.

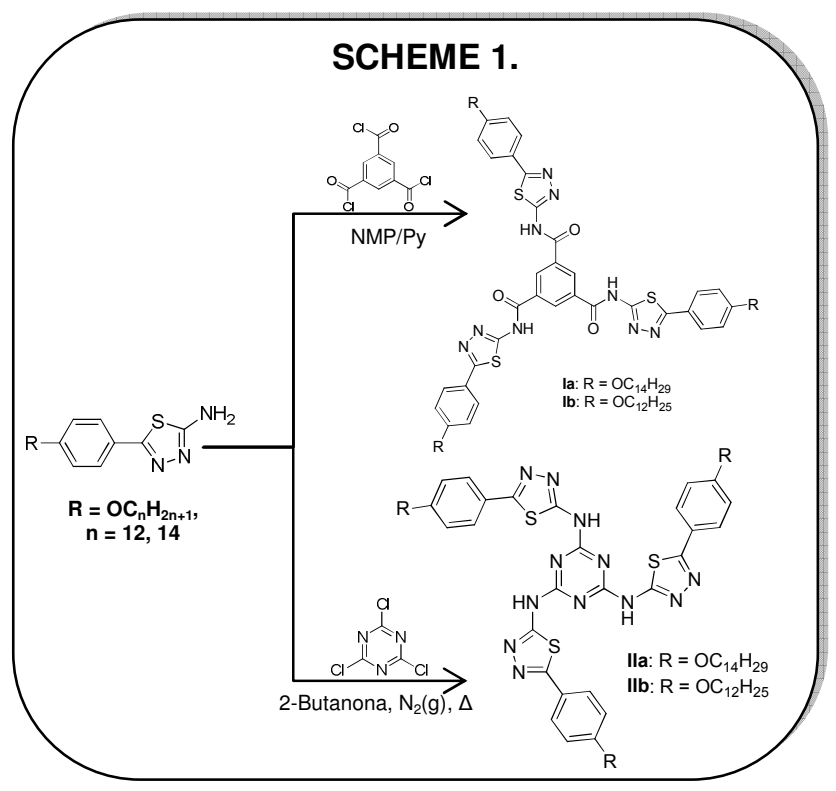

\section{RESULTS AND DISCUSSION}

Compounds la-b and Ila-b are thermotropic liquid crystals. In all the cases a columnar mesophase was observed. The mesophase exhibited by these compounds were identified according to their optical textures which were observed by optical polarizing microscopy (Figure 1).

The amide and amine function favors the stabilization of the columnar mesophase due to the formation of intermolecular hydrogen bonding. The compounds exhibited moderate and wide mesomorphic temperature ranges (Table 1). The trisamides $\mathbf{l a}$ and $\mathbf{~} \mathbf{b}$ have a mesomorphic range of $25^{\circ} \mathrm{C}$ and $42^{\circ} \mathrm{C}$, respectively, which are influenced by the length of the terminal alkoxy chains so we can be conclude that as increases the length of peripheral chain in two carbon atoms the mesomorphic range is lower. In the case of the trisamines lla-b, the thermal stability of mesophase is higher than the trisamides la-b until the partial decomposition of the compound which occur in $245^{\circ} \mathrm{C}$ for Ila and $250^{\circ} \mathrm{C}$ for Illb.
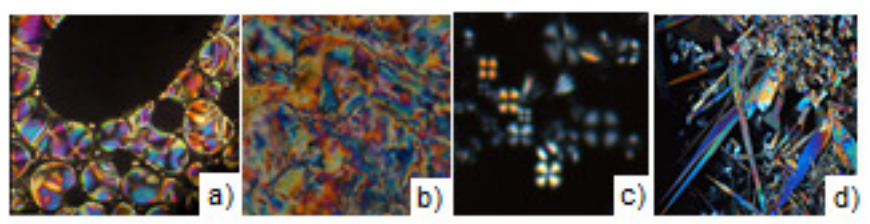

Figure 1. Optical micrographs (magnification: $x 10$ ) of $(a)$ la, at $90^{\circ} \mathrm{C}$; (b) Ib, at $102^{\circ} \mathrm{C}$; (c) Ila at $153^{\circ} \mathrm{C}$; (d) Ilb at $130.1^{\circ} \mathrm{C}$.

Table 1. Transition temperatures $(\stackrel{\circ}{-})$ for compounds of series la-b and lla-b. $\mathbf{d}=$ decomposition temperature.

\begin{tabular}{cc}
\hline Compound & Transition Temperature $\left({ }^{\circ} \mathrm{C}\right)$ \\
\hline la & $\mathrm{Cr} 70 \mathrm{Col}_{x} 95 \mathrm{I}$ \\
\hline Ib & $\mathrm{Cr} 95 \mathrm{Col}_{\mathrm{x}} 137 \mathrm{I}$ \\
\hline Ila & $\mathrm{Cr} 134 \mathrm{Col}_{x} 245 \mathrm{~d}$ \\
\hline Ilb & $\mathrm{Cr} 121 \mathrm{Col}_{\times} 250 \mathrm{~d}$ \\
\hline
\end{tabular}

\section{CONCLUSION}

In conclusion, we have described the synthesis and mesomorphic properties of new columnar liquid crystals, based on trisamides and trisamines incorporating 1,3,4-thiadiazole heterocycle..

\section{ACKNOWLEDGEMENTS}

This work was supported by FONDECYT (Grant 1100140), CONICYT (Postgraduate Scholarship) and "Dirección de Investigación" of the University of Concepción.

\section{REFERENCES}

Stackhouse, P. J.; Wilson, A.; Lacey, D.; Hird, M. Liquid Crystals. 2010, 9, 1191.

${ }^{2}$ Parra, M.; Vergara, J.; Alderete, J.; Zuñiga, C. Liquid Crystals. 2004, 11, 1531. 